\title{
- Method Development and Validation for the Analysis of Apalutamide in Human Plasma by LC-MS/MS
}

\author{
G Sai Uday Kiran'1, P Sandhya ${ }^{2}$ \\ 'Research Scholar, Career Point University, Kota, Rajasthan-325003, India; ${ }^{2}$ Research Supervisor, Career Point University, Kota, \\ Rajasthan-325003, India.
}

ection: Healthcare

ISI Impact Factor

(2020-21): 1.899

IC Value (2020): 91.47

SJIF $(2020)=7.893$

(c) (7) (8)

Copyright@IJCRR

\section{ABSTRACT}

Introduction: Highly specific, selective and accurate liquid chromatography/tandem mass spectrometry (LC-MS/MS) technique was desirable for the assessment of apalutamide in human plasma.

Aims: To develop and validate LC-MS/MS method for the analysis of apalutamide in human plasma.

Methodology: Drug and internal standard were extracted utilizing liquid-liquid extraction was performed using ethyl acetate. Reversed phase high performace liquid chromatography (RP-HPLC) was carried out using Inertsil $(50 \times 4.6 \mathrm{~mm}$ i.d., $5 \mu \mathrm{m}) \mathrm{C}_{18}$ analytical column with a simple isocratic mobile phase composed of $0.1 \%$ formic acid and acetonitrile, $(20: 80, v / v)$. Detection was executed on a triple quadrupole mass spectrometer retaining electrospray ionization method, operating in multiple reaction monitoring (MRM), with the transitions of $\mathrm{m} / \mathrm{z} 478.09 \rightarrow 447.05, \mathrm{~m} / \mathrm{z} 445.14 \rightarrow 267.12$ for apalutamide, canagliflozin, respectively, in the positive ionization mode. The linearity was processed a concentration range of 300-12000 ng/mL for the analyte.

Results: The method was validated in accordance with the FDA guidelines for bioanalytical method. All obtained recoveries were higher than $93.0 \%$ while the accuracy was in the range of -4.32 to $2.45 \%$ of relative error and the relative standard deviation was below $4.21 \%$ for all investigated drugs by the proposed method.

Conclusion: The validated method has highly sensitive and nice recoveries values from plasma, utilized for the bioequivalence and pharmacokinetic studies.

Key Words: Apalutamide, Prostate cancer, LC-MS/MS, Validation, Linearity, Accuracy

\section{INTRODUCTION}

Apalutamide drug chemically titled as 4-[7-[6-cyano-5 -(trifluoromethyl) pyridin-3-yl] -8-oxo -6-sulfanylidene-5, 7-diazaspiro[3.4]octan-5-yl] -2-fluoro- $N$-methylbenzamide. Its chemical formula and molecular mass are $\mathrm{C}_{21} \mathrm{H}_{15} \mathrm{~F}_{4} \mathrm{~N}_{5} \mathrm{O}_{2} \mathrm{~S}$ and $477.435 \mathrm{~g} / \mathrm{mol}$ respectively (Figure 1). This drug is marketing in the brand of Erleada, belongs to NSAA (nonsteroidal antiandrogen) medicine. It is utilized in management of cancers of prostate ${ }^{1-3}$ specifically, this drug utilized in combination with castration to treat NM-CRPC (nonmetastatic castration-resistant prostate cancer). It is taken by oral route. Persistent androgen receptor(AR) beckoning is routine process of CRPC(castration-resistant prostate cancer), ascribed to ARgene magnification, ARgene mutation, amplified AR countenance or improved androgen synthesis in prostate cancers. Drug acts against AR and bound-site in the ligand bounding domain of receptor with the IC 50 of $16 \mathrm{nM} \cdot{ }^{4-7}$ On bounding, drug prevents ARsignalling, obstructs DNA bounding, and inhibits AR-mediated gene transcription. It damages translocation of AR from cytoplasm to nucleus. Then decreases concentration of AR obtainable to react with androgen response-elements (AREs). Upon management with this drug, AR was not employed to the DNA promoter-regions. ${ }^{7-10}$

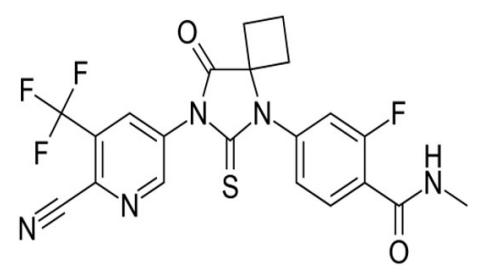

Figure 1: Structure of apalutamide.

\section{Corresponding Author:}

Dr. P. Sandhya, Research Supervisor, Career Point University, Kota, Rajasthan-325003, India. Contact: +91-9849395823; Email: sandhyapasikanti@gmail.com

ISSN: 2231-2196 (Print)

Received: 10.10 .2021
ISSN: 0975-5241 (Online)

Revised: 14.11 .2021
Accepted: 16.12 .2021
Published: 15.02 .2022 
Literature review on apalutamide reveals that three analytical approaches on high performance liquid chromatography ${ }^{11}$ and liquid chromatography-tandem mass spectrometry ${ }^{12,13}$ were reported for the estimation of apalutamide in plasma, API and formulations. Present work was aimed to develop a highly specific, selective and accurate LC-MS/MS technique was desirable for the assessment of apalutamide in human plasma.

\section{MATERIALS AND METHODS}

\section{Reagents and chemicals}

The standards of apalutamide (purity :99.51\%) and canagliflozin (purity :99.82\%) used as internal standard (IS) were gained from the MSN Labs, Hyderabad, India. Methanol and acetonitrile of HPLC purity were acquired from Merck, Mumbai, India. Deionized water was produced by a Milli-Q water system (Millipore, MA, USA).

\section{LC-MS/MS system and its conditions}

The LC-MS/MS system consisting of an Agilent/1200 liquid chromatographic instrument with a binary pump-SL and an Agilent/6460 triple-quadrupole mass spectrometer with electrospray ionization (ESI) source (CA, USA). Chromatographic data was processed by a MassHunter version B.01.04 software. Inertsil $(50 \times 4.6 \mathrm{~mm}$ i.d., $5 \mu \mathrm{m}) \mathrm{C}_{18}$ analytical column with a simple isocratic mobile phase composed of $0.1 \%$ formic acid and acetonitrile, $(20: 80, v / v)$. Detection was executed on a triple quadrupole mass spectrometer retaining electrospray ionization method, operating in multiple reaction monitoring (MRM), with the transitions of $\mathrm{m} / \mathrm{z}$ $478.09 \rightarrow 447.05, \mathrm{~m} / \mathrm{z} 445.14 \rightarrow 267.12$ for apalutamide, canagliflozin, respectively, in the positive ionization mode. The flow rate of $0.80 \mathrm{~mL} / \mathrm{min}$ and collision energy of $20 \mathrm{eV}$ were utilized in the chromatographic elution. The injection volume and auto-sampler temperatures were set to $10 \mu \mathrm{L}$ and $5.0{ }^{\circ} \mathrm{C}$ respectively. MS/MS analysis was controlled using multiple reaction monitoring (MRM) scan modes. The MS/ MS setting parameters were set as follows: source temperature, $450{ }^{\circ} \mathrm{C}$; capillary voltage, $6.0 \mathrm{kV}$; nebulizer gas pressure, $50 \mathrm{psi}$ and drying gas $\left(\mathrm{N}_{2}\right)$ flow, $10 \mathrm{~L} / \mathrm{min}$.

\section{Protocol for standard and quality controls}

$1.0 \mathrm{mg} / \mathrm{mL}$ individual stock solutions of apalutamide and IS were prepared in $90 \%$ acetonitrile in water (diluent) separately. The stock solution of apalutamide was then serially diluted with diluent to obtain the working solutions. The IS working solution of $300 \mathrm{ng} / \mathrm{mL}$ was also processed by diluting the IS stock solution with diluent. All the solutions were kept at $-20^{\circ} \mathrm{C}$ and brought to room temperature before use.

Calibration standard standards of apalutamide (300, 850, $2100,4000,6000,8000,10000$ and $12000 \mathrm{ng} / \mathrm{mL}$ ) were ob- tained by spiking the appropriate working solutions to blank plasma. Quality control (QC) samples at low, medium and high concentrations $(840,6000$ and $9000 \mathrm{ng} / \mathrm{mL})$ were prepared separately in the similar manner.

\section{Protocol for sample preparation}

A $100 \mu \mathrm{L}$ aliquot of plasma sample was located in a $10 \mathrm{~mL}$ plastic tube followed by addition of $125 \mu \mathrm{L}$ of IS working solution was then added to all samples except the blank samples. The mixture was extracted with $5.0 \mathrm{~mL}$ of diethyl ether by vortex-mixing at a high speed for $5.0 \mathrm{~min}$ and shaking for $20 \mathrm{~min}$. Thereafter, the samples were centrifuged at $5.0{ }^{\circ} \mathrm{C}$ for $15 \mathrm{~min}$ at $5000 \mathrm{rpm}$. The upper organic layer was transferred to clean glass tubes and evaporated to dryness under a gentle stream of nitrogen. The dry residue was reconstituted with $100 \mu \mathrm{L}$ of mobile phase and a $10 \mu \mathrm{L}$ aliquot was injected into the LC-MS/MS system for analysis.

\section{Analytical method validation}

The analytical method was validated to meet the acceptance criteria of the Food \& Drug Administration (FDA) guidelines. ${ }^{14,15}$

\section{RESULTS AND DISCUSSION}

\section{Mass spectrometry}

When the neat solution of apalutamide was infused a precursor ion of $\mathrm{m} / \mathrm{z} 478.09$ was observed in the positive ionization mode. Upon fragmentation of the precursor ion, fragments of $\mathrm{m} / \mathrm{z} 451.08,449.06$ and 447.05 were detected. Fragment of apalutamide ion with $\mathrm{m} / \mathrm{z} 447.05$ was detected with the greatest intensity. Due to commercial unavailability of the stable isotope labeled IS we have explored several possibilities and chose canagliflozin as a proper IS. Under the optimal conditions, the MRM transitions of $\mathrm{m} / \mathrm{z} 478.09 \rightarrow 447.05$ for apalutamide, and $\mathrm{m} / z 445.14 \rightarrow 267.12$ for IS were monitored.

\section{Selectivity and specificity}

No interference peak was detected for apalutamide and IS from plasma samples. The typical chromatograms of blank plasma and plasma spiked with $300 \mathrm{ng} / \mathrm{mL}$ of apalutamide (LLOQ level) and IS were shown in Fig. 2. The retention times of apalutamide and IS were approximately $0.71 \mathrm{~min}$ and $1.18 \mathrm{~min}$, respectively. ${ }^{16}$

\section{Linearity of calibration curves and sensitivity}

Calibration curves were processed for each batch analysis in the concentration ranges of 300-12000 ng/mL for apalutamide in plasma (Table 1). The mean regression equation obtained for apalutamide was: $y=0.0037 x+0.0081(n=6)$ for apalutamide, where $y$ is the ratios of analytes to IS and $x$ is the plasma concentrations. ${ }^{17-19}$ 


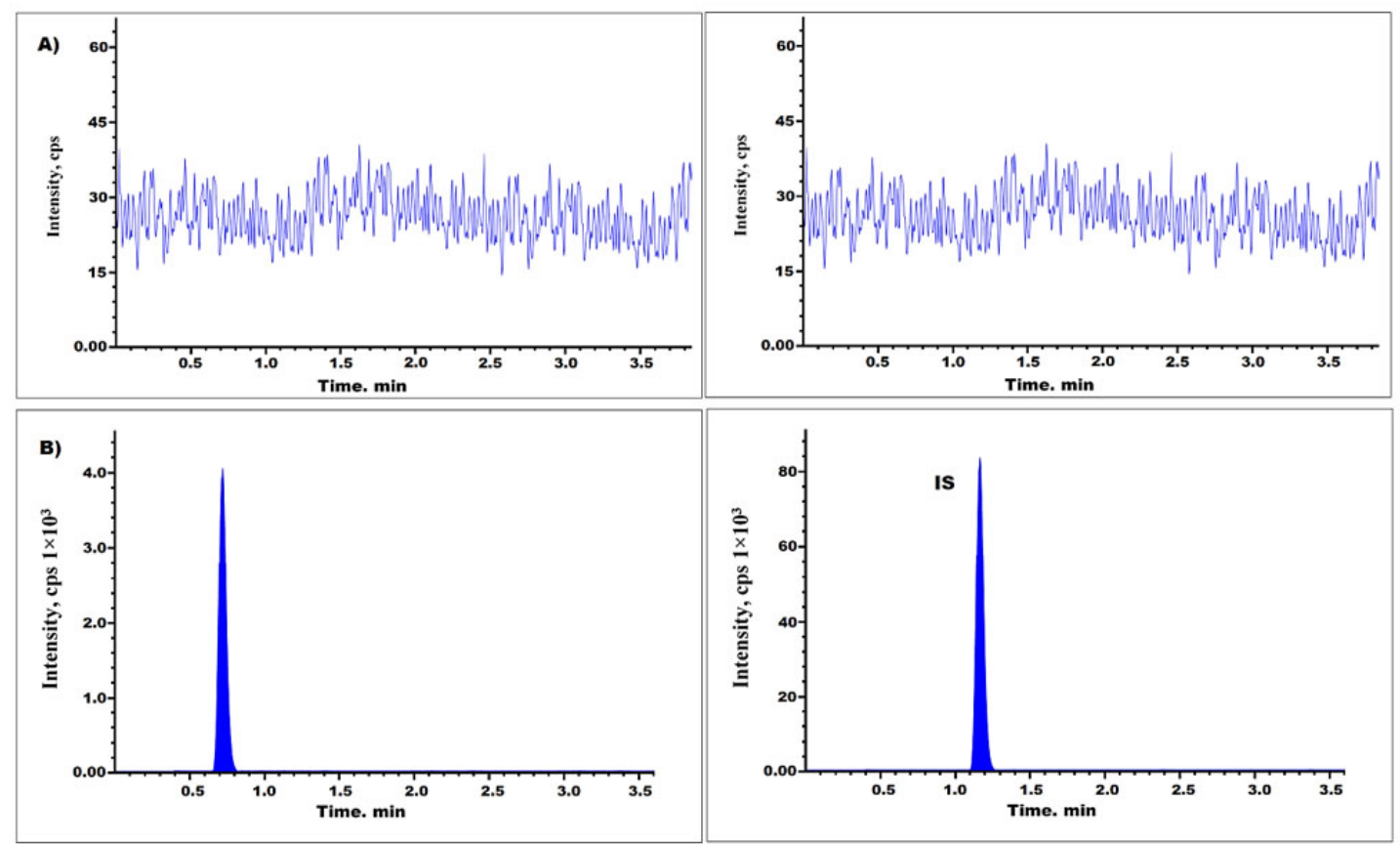

Figure 2: Representative chromatograms of apalutamide A) Blank and B) LLOQ samples.

The LLOQ of the analyte was set to $300 \mathrm{ng} / \mathrm{mL}$ with precision and accuracy less $3.54 \%$ and the $\mathrm{S} / \mathrm{N}$ values were more than 10 .

Table 1: Calibration standards for apalutamide.

\begin{tabular}{lcccc} 
CS-ID & $\begin{array}{c}\text { Concentration } \\
(\mathbf{n g} / \mathrm{mL})\end{array}$ & Mean $^{\mathrm{a}}(\mathrm{ng} / \mathrm{mL})$ & $\% \mathrm{RSD}$ & $\% \mathrm{RE}$ \\
CS-1 & 300 & 293.01 & 2.85 & 2.33 \\
CS-2 & 850 & 816.07 & 3.16 & 3.98 \\
CS-3 & 2100 & 2029.54 & 2.98 & 3.35 \\
CS-4 & 4000 & 4035.40 & 3.94 & -0.89 \\
CS-5 & 6000 & 5967.29 & 1.81 & 0.56 \\
CS-6 & 8000 & 8135.99 & 2.73 & -1.69 \\
CS-7 & 10000 & 10139.96 & 1.18 & -1.399 \\
CS-8 & 12000 & 12225.72 & 2.55 & -1.88 \\
\hline
\end{tabular}

a:6 replicates; RSD: Relative standard deviation; RE: Relative Error

\section{Precision, accuracy and recovery}

Intra-day and inter-day precision and accuracy are shown in Table 2 and Fig. 3. Intra-day precision ranged from $2.41 \%$ to $4.21 \%$ (RSD) for apalutamide, while the accuracy was within -4.32 to $2.45 \%$ of relative error. Similarly, for the inter-day experiments, the precision varied from $1.96 \%$ to $4.25 \%$ (RSD) for apalutamide, while the accuracy was within -2.77 to $4.37 \%$ of relative error. This proved that the method was accurate and precise over the range of the assay. ${ }^{20}$

The mean recoveries of apalutamide ranged from $93.81 \%$ to $104.62 \%$ at three QC levels (Table 3). The simple liquid-liquid extraction procedure showed that apalutamide and the IS (97.94\%) were excellently recovered in plasma. ${ }^{18}$

Table 2: Intra- and inter-day precision and accuracy of the LC-MS/MS method to determine apalutamide in plasma $(n=3$ days, 6 replicates per day).

\begin{tabular}{lcccccc}
$\begin{array}{l}\text { Spiked } \\
\text { conc. }(\mathrm{ng} / \\
\mathrm{mL})\end{array}$ & $\begin{array}{c}\text { Measured conc. } \\
(\text { mean } \pm \text { SD: } \mathbf{n g} / \mathrm{mL})\end{array}$ & $\begin{array}{c}\text { Precision } \\
(\mathrm{RSD} \%)\end{array}$ & $\begin{array}{c}\text { Accuracy } \\
(\mathrm{RE} \%)\end{array}$ & $\begin{array}{c}\text { Measured conc. } \\
(\text { mean } \pm \text { SD: } \mathbf{n g} / \mathrm{mL})\end{array}$ & $\begin{array}{c}\text { Inter-day }(\mathbf{n}=6 \times 3) \\
\text { Precision } \\
(\mathrm{RSD} \%)\end{array}$ & $\begin{array}{c}\text { Accuracy } \\
(\mathrm{RE} \%)\end{array}$ \\
\hline 300 & $286.03 \pm 3.49$ & 2.41 & -1.97 & $313.95 \pm 13.95$ & 3.54 & 1.54 \\
840 & $800.97 \pm 9.77$ & 4.21 & 2.45 & $879.06 \pm 39.06$ & 4.21 & -2.51 \\
6000 & $5720.94 \pm 69.77$ & 2.86 & -4.32 & $6279.07 \pm 279.06$ & 2.54 & -2.77 \\
9000 & $8581.45 \pm 104.65$ & 3.54 & -2.441 & $9418.61 \pm 418.61$ & 1.96 & 4.37 \\
\hline
\end{tabular}

RSD: Relative standard deviation; RE: relative error. 

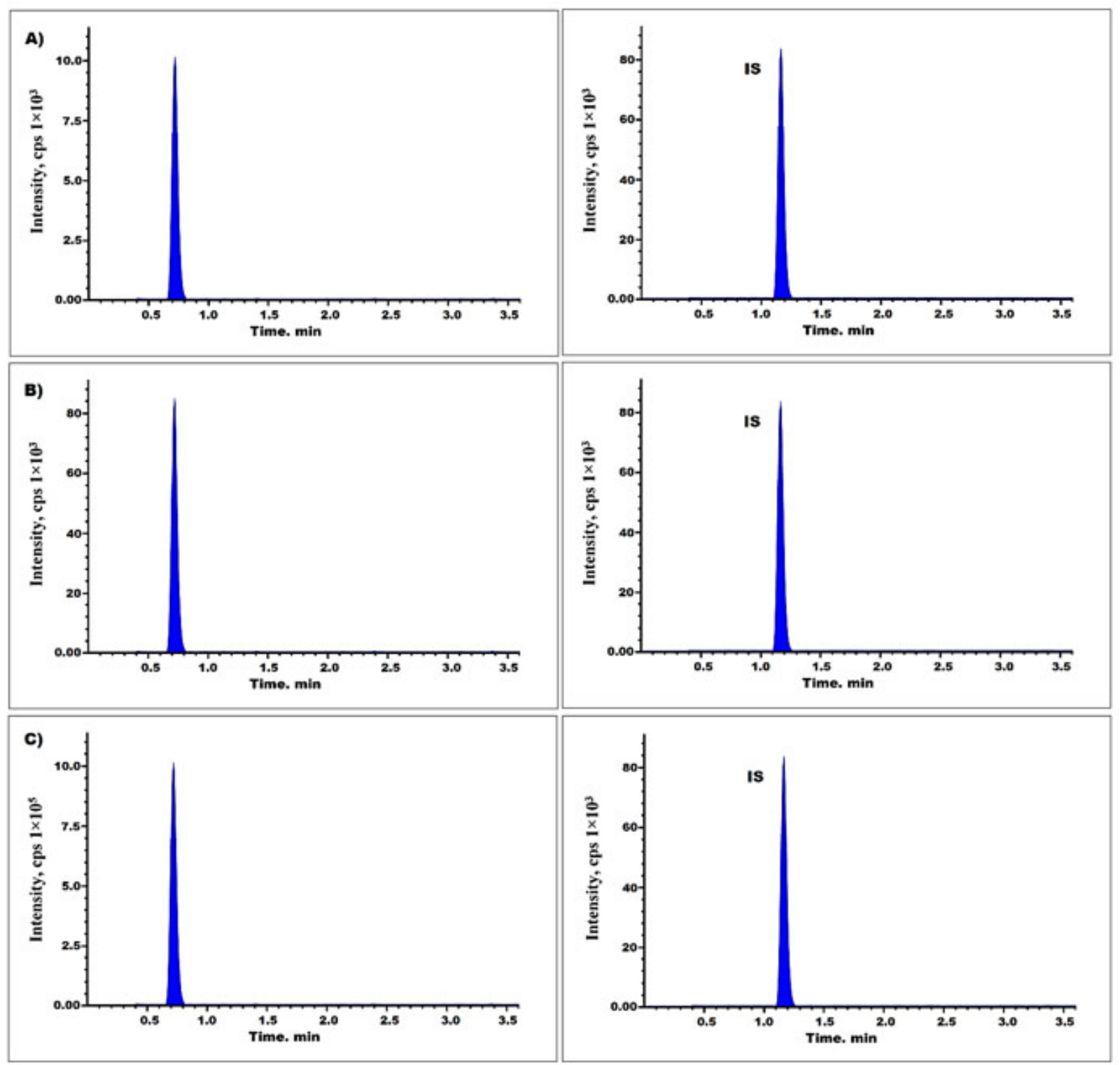

Figure 3: Representative chromatograms apalutamide at A) LQC B) MQC and C) HQC levels.

Table 3: Extraction recovery rates of analytes.

\begin{tabular}{lccccc} 
Concentration level & $\mathbf{X}$ & $\mathbf{Y}$ & \% Recovery & \% Mean recovery & \%RSD \\
LQC & 10996 & 10715.6 & 97.45 & 98.63 & 4.55 \\
MQC & 82891 & 77760.05 & 93.81 & & \\
HQC & 119920 & 125460.3 & 104.62 & \\
IS & 86003 & 84231.34 & 97.94 & & \\
\hline
\end{tabular}

$\mathrm{X}$, mean recoveries of unextracted samples; $\mathrm{Y}$, mean recoveries of extracted samples.

\section{Matrix effects}

The results of matrix effects are shown in Table 4. The corresponding peak area ratios of the analyte/IS dissolved with blank plasma extracts to those dissolved with mobile phase ranged from $94.85 \%$ to $103.34 \%$ for apalutamide at LQC level and $95.72 \%$ to $104.08 \%$ at HQC level. These results suggested that the matrix effects of the analytes were negligible under the present LC-MS/MS conditions. ${ }^{19,20,22}$ 
Table 4: Matrix effect for apalutamide at LQC and HQC levels.

\begin{tabular}{|c|c|c|c|c|c|c|}
\hline \multirow[b]{2}{*}{ S. No } & \multicolumn{3}{|c|}{ LQC } & \multicolumn{3}{|c|}{ HQC } \\
\hline & $\begin{array}{l}\text { peak area in } \\
\text { absence of matrix }\end{array}$ & $\begin{array}{l}\text { peak area in } \\
\text { presence of } \\
\text { matrix }\end{array}$ & $\begin{array}{l}\text { Matrix } \\
\text { factor }\end{array}$ & $\begin{array}{c}\text { peak area in } \\
\text { absence of } \\
\text { matrix }\end{array}$ & $\begin{array}{c}\text { peak area in } \\
\text { presence of } \\
\text { matrix }\end{array}$ & $\begin{array}{l}\text { Matrix } \\
\text { factor }\end{array}$ \\
\hline 1 & 818 & 788 & 96.42 & 8814 & 8585 & $97 \cdot 41$ \\
\hline 2 & 821 & 809 & 98.62 & 9028 & 8697 & 96.34 \\
\hline 3 & 798 & 816 & $103 \cdot 34$ & 8895 & 8774 & 98.64 \\
\hline 4 & 853 & 873 & 102.44 & 9026 & 9337 & 103.45 \\
\hline 5 & 831 & 808 & 97.24 & 9034 & 9402 & 104.08 \\
\hline 6 & 793 & 752 & 94.85 & 8944 & 8561 & $95 \cdot 72$ \\
\hline Mean & & & 98.651 & & & 99.273 \\
\hline$\pm \mathrm{SD}$ & & & 3.142 & & & 3.62 \\
\hline \% RSD & & & 3.185 & & & 3.651 \\
\hline
\end{tabular}

RSD: Relative standard deviation; SD: standard deviation.

\section{Stability tests}

The stability of apalutamide was tested after subjecting the QC samples to different storage conditions. The applied conditions includes short term stability at room temperature for $8 \mathrm{~h}$, long term stability after storage at $-20{ }^{\circ} \mathrm{C}$ for 30 day, three complete freeze-thaw cycles (freezing at $-20{ }^{\circ} \mathrm{C}$ for $12 \mathrm{~h}$ ) and the processed sample (extract) stability after $24 \mathrm{~h}$ at $4{ }^{\circ} \mathrm{C}$. The stability results of QC samples at plasma and processed sample are listed in Table 5. The calculated accuracies for apalutamide determination were within the range of $94.67 \%-102.21 \%$ of the nominal concentration which lies within the acceptable range. As a result, apalutamide was deemed to be stable under different studied storage conditions. ${ }^{15-23}$

Table 5: The stability data of apalutamide.

\begin{tabular}{|c|c|c|c|c|c|c|}
\hline \multirow[t]{2}{*}{ Storage condition } & \multicolumn{2}{|c|}{ LQC $840 \mathrm{ng} / \mathrm{mL}$} & \multicolumn{2}{|c|}{ MQC $6000 \mathrm{ng} / \mathrm{mL}$} & \multicolumn{2}{|c|}{ HQC $9000 \mathrm{ng} / \mathrm{mL}$} \\
\hline & $\begin{array}{l}\text { Accuracy } \\
\text { (Mean\%) }\end{array}$ & $\begin{array}{c}\text { Precision } \\
\text { (RSD\%) }\end{array}$ & $\begin{array}{l}\text { Accuracy } \\
\text { (Mean\%) }\end{array}$ & $\begin{array}{c}\text { Precision } \\
\text { (RSD\%) }\end{array}$ & $\begin{array}{l}\text { Accuracy } \\
\text { (Mean\%) }\end{array}$ & $\begin{array}{c}\text { Precision } \\
\text { (RSD\%) }\end{array}$ \\
\hline 30 day at $-20{ }^{\circ} \mathrm{C}$ & 95.61 & 2.56 & 94.67 & 1.56 & 95.23 & 2.18 \\
\hline Extract, 24 h at $4{ }^{\circ} \mathrm{C}$ & 98.74 & 1.83 & 102.34 & 2.94 & 98.48 & 3.84 \\
\hline Room temp., 8 h & 97.63 & 2.46 & $95 \cdot 93$ & 2.35 & 101.34 & 2.45 \\
\hline 3 freeze-thaw cycles & 102.21 & $3 \cdot 5^{2}$ & 96.35 & $3 \cdot 72$ & 97.91 & 3.16 \\
\hline
\end{tabular}

RSD: Relative standard deviation.

\section{CONCLUSION}

A specific and validated LC-MS/MS technique was developed for the estimation of apalutamide drug in human plasma. Validation process was in compliance with FDA guidelines and the procedure was Ecofriendly, precise and sensible with LLOQ at $300 \mathrm{ng} / \mathrm{mL}$ and rapid with total run time equals 3.5 $\min$. The intra-day and inter-day accuracies were within -4.32 to $4.37 \%$ of relative error and the relative standard deviation of precision was less than $4.21 \%$. The drug was sufficiently stable under different analytical conditions. LLE method was optimized for apalutamide extracting from plasma with mean percent recoveries of $97.45 \%$ by utilizing the canagliflozin as an internal standard. The validated method has highly sensitive and nice recoveries values from plasma, utilized for the bioequivalence and pharmacokinetic studies.

\section{ACKNOWLEDGEMENT}

Authors acknowledge immense help received from the scholars whose articles are cited and included in reference to the manuscript. The authors are grateful to all the authors/ editors/publisher of those articles, journals, and books from where the literature of this article has been reviewed and discussed. There is no source of funding for this study. There is no conflict of interest in this study.

Source(s) of funding: No funding is involved.

Conflicts of interest: The authors declare no conflicting interest.

Author's contribution: All the authors contributed equally. 


\section{REFERENCES}

1. https://www.accessdata.fda.gov/drugsatfda_docs/ label/2018/210951s000lbl.pdf

2. Rathkopf DE,. (October 2013). Phase I study of ARN-509, a novel antiandrogen, in the treatment of castration-resistant prostate cancer. J of Cli Onco. 2013;31(28): 3525-30.

3. Al-Salama ZT. Apalutamide: First Global Approval. Drugs. 2018;78: 699-705.

4. Chong JT, Oh WK, Liaw BC. Profile of apalutamide in the treatment of metastatic castration-resistant prostate cancer: evidence to date. OncoTargets Ther. 2018;11:2141-2147.

5. Dellis AE, Papatsoris AG. Apalutamide: The established and emerging roles in the treatment of advanced prostate cancer. Expert Opin Investig Drugs. 2018;27: 553-559.

6. Clegg NJ, Wongvipat J, Joseph JD, Tran C, Ouk S, Dilhas A. ARN-509: a novel antiandrogen for prostate cancer treatment. Cancer Research. 2012;72(6):1494-503.

7. https://www.fda.gov/NewsEvents/Newsroom/PressAnnouncements/ucm596768.htm

8. https://www.medscape.com/viewarticle/892708

9. Schweizer MT, Antonarakis ES. Abiraterone and other novel androgen-directed strategies for the treatment of prostate cancer: a new era of hormonal therapies is born. Therapeutic Advances in Urology. 2012;4 (4):167-78.

10. Leibowitz-Amit R, Joshua AM. Targeting the androgen receptor in the management of castration-resistant prostate cancer: rationale, progress, and future directions. Cur Onco. 2012;19:S22-31.

11. Kiranjyothi R, Balakrishnan M, Chandrasekhar KB. Stability indicating RP-HPLC method development and validation of for estimation of apalutamide in tablet dosage form. J Global Trends Pharm Sci, 2019; 10(4): 6759 - 6767.

12. Saini NK, Sulochana SP, Kiran V, Zainuddin M, Mullangi R. A novel dried blood spot LC-MS/MS method for the quantification of apalutamide in mice whole blood: Application to pharmacokinetic study in mice. J P Biomed Ana. 2018;32(11):4344-4349.

13. Hallur G, Purra BR, Sulochana SP, Saini NK, Daram P, Zainuddin M, Mullangi R. Validation of an LC-ESI-MS/MS method for the determination of apalutamide, a novel non-steroidal anti-androgen in mice plasma and its application to a pharmacokinetic study in mice. J Pharm Biomed Ana. 2018;153:260-266.

14. FDA Guidance for Industry, Bioanalytical Method Validation, US Department of Health and Human Services, Food and Drug Administration, Centre for Drug Evaluation and Research (CDER), Center for Veterinary Medicine (CVM) May 2001.

15. European Medicines Agency, Guideline on bioanalytical method validation 2011

16. ICH guidelines for validation of analytical procedures: text and methodology. Q2(R1) ICH, Geneva; 2005. p. 1-14.

17. Nirav P Patel, Highly sensitive LC-MS/MS method to estimate doxepin and its metabolite nordoxepin in human plasma for a bioequivalence study Highly sensitive LC-MS/MS method to estimate doxepin and its metabolite nordoxepin in human plasma for a bioequivalence study. J. Pharm. Anal, 2017; 6:145-50.

18. Jaivik V, Shaha Priyanka A, Shaha Priya V, Shahb M, Sanyalc PS, Shrivastav. Fast and sensitive LC-MS/MS method for the simultaneous determination of lisinopril and hydrochlorothiazide in human plasma. J of Phar Ana. 2017;7:163-169.

19. Cheruku S, Bhikshapathi DVRN. Method development and validation for the quantification of pexidartinib in biological samples by LC-MS/MS. IJPR. 2021;13(1):6522-30

20. Nagalakshmi V, Srinivas Rao G, Gayathri Devi N, Mohan S. RP-HPLC method for simultaneous estimation of vildagliptin and metformin in bulk and pharmaceutical formulations. IJCRR. 2021. 13(7)112-117.

21. Patel DS, Sharma N, Patel MC. Development and validation of a selective and sensitive LC-MS/MS method for determination of cycloserine in human plasma: application to bioequivalence study. J. Chrom. B, 2011: 879: 2265-2273.

22. Titier K, Castaing N, Le-Deodic M. Quantification of tricyclic antidepressants and monoamine oxidase inhibitors by high-performance liquid chromatography-tandem mass spectrometry in whole blood, J. Anal. Toxicol., 1997;21:200-207.

23. Hindu K, Vinodhini C, Srinivas SK, Rajan SM, Chitra K, Mangathayaru K. Validated RP-HPLC method for quantification of paclitaxel in human plasma - eliminates negative influence of cremophor EI. IJCRR. 2018;10(13):5-10. 